\title{
Effect of Analytical Extraction Methods and Storage Time on the Quality of Moringa Seed Oil
}

\author{
J. O. Y. Ilesanmi ${ }^{\text {a }}$, J. B. Hussein ${ }^{\mathrm{a}, *}$, H. A. Yahuza ${ }^{\mathrm{a}}$, I. Nkama ${ }^{\mathrm{b}}$ \\ ${ }^{a}$ Department of Food Science and Technology, Modibbo Adama University of Technology, Yola, Adamawa State, \\ NIGERIA. \\ ${ }^{b}$ Department of Food Science and Technology, University of Nigeria, Nsukka, Enugu State, NIGERIA.
}

\begin{abstract}
The effect of extraction methods and storage time on the quality of moringa seed oil was investigated. Cold water, hot water, and n-hexane extraction methods were used while the extracted oils were stored at room temperature for six months. The chemical properties, qualitative and quantitative phytochemical screening of the oils were determined using standard methods. The n-hexane had the highest yield of 56\%, hot water 40\%, and cold water $30 \%$. The chemical properties ranged as follows: peroxide value: (12.98-22.50, 10.36-33.12 and 9.12-23.93 Meq/kg), saponification value: (189.01-160.23, 222.17-122.72 and 184.17-110.82 $\mathrm{mgKOH} / \mathrm{g})$, iodine value: (65.17-14.37, 60.49-16.25 and 59.46-16.84 mg/wij's) and acid value: (14.58-74.14, 12.99-78.07 and 17.96-46.19 $\mathrm{mgKOH} / \mathrm{g}$ ), respectively for cold water, hot water, and n-hexane. The phytochemical screening indicated the presence of flavonoids, coumarins, and terpenoids. Moringa olelifera seed oils are good sources of alternative oil for both commercial and industrial applications.
\end{abstract}

Keywords: Moringa seeds, oil, extraction methods, storage time, phytochemical properties

\section{INTRODUCTION}

The increasing awareness of the importance of seed oils as sources of food, biofuel, healthenhancing compounds (functional foods), feedstock for industrial polymers, and many other industrial products have awakened the researchers' interest in this area. However, the dual usage of some of these oilseeds and an increase in their demands have led to their scarcity and relatively higher price [1]. Therefore, investigation on ways to improve the oil from oilseeds yields and the quality of the oil itself to meet the global needs becomes necessary to take advantage of more oilseeds.

Oils can be extracted from various oilseeds which can serve as foods, nutraceuticals, skincare products, aromatherapies, fuels, and industrial lubricants. Oilseeds such as peanut, soybean, cottonseed, sunflower, palm kernel, olive, rapeseeds, and coconut are the largest source of vegetable oils. The oils extracted from these oilseeds have played vital roles to provide comfort in human lives in various aspects. Outside the realm of food manufacture, these oils feature in various industrial uses ranging from the manufacture of soap

*Corresponding author (Tel: +234(0) 806059 7615)

Email addresses: yemisi_akinyele@yahoo.com (J. O. Y. Ilesanmi), jbhusseinO1@mautech.edu.ng (J. B. Hussein), hindatyahuza@gmail.com (H. A. Yahuza), nkama.iro@unn.edu.ng (I. Nkama) to the production of lubricants, varnishes, paints, and plastics [2]. However, the overdependence on these edible oils has led to a general rise in their prices which is detrimental to middle-class people. Thus, the need to exploit the potential of other agricultural produce such as moringa seeds for the source of edible oils.

Moringa seeds are edible in both fresh and dried forms and serve as helpful botanical and herbal remedies, nutritional supplements and industrial and agricultural purposes [3]. Moringa seeds have valuable properties such as antibiotic and anti-inflammatory that enable them to treat various illnesses and conditions like arthritis, rheumatism, gouts, sexually transmitted diseases, urinary infections, boils, and even epilepsy [4]. The seeds are also sources of minerals (potassium, phosphorus, sodium, zinc, magnesium, and calcium), micronutrients (provitamin A and vitamin B group), and bioactive compounds (flavonoids, saponins, sterols, phytates, and trypsin inhibitors) [5]. [4] reported that moringa seeds contain $38-40 \%$ oil which has an excellent quality of $73 \%$ oleic acid similar to olive oil, which gives it additional beneficial properties. [6] also reported that moringa seeds are rich in vegetable oil and high in nutrients due to proteins, vitamins, and various phenolic compounds in them. Moringa seed oil is rich in omega fatty acids and antioxidants, which soothe and protect the skin. The antioxidants act as natural preservatives, making them oil resistant to 
rancidity and allowing more extended shelf life. The oil was found to contain dominant saturated acids; palmitic and behenic (both up to $6.40 \%$ ), high level of unsaturated fatty acids, especially oleic $(71.60 \%), \beta$-sitosterol $(45.58 \%)$, stigmasterol (23.10\%), campesterol (15.81\%). At the same time $\sigma-, \gamma-$, and $\delta$ - tocopherols were detected up to levels of $15.38 \mathrm{mg} / \mathrm{kg}, 25.40 \mathrm{mg} / \mathrm{kg}$, and $15.51 \mathrm{mg} / \mathrm{kg}$ of oil respectively [7]. Nevertheless, the high lipid content $(13-46 \%)$ of this moringa seed considered it as oilseeds and the oils are edible with multipurpose uses. Thus the increase in the production, characterization, and utilization of this seed in vegetable oils to meet global needs.

Recently, many researchers such as [3, 4, 814] have worked on the extraction and characterization of oil from moringa seeds as an alternative to meet the growing demand of edible oils. The extractions were basically done by three major methods; solvent extraction method, mechanical/hydraulic pressing method, and rendering method. The solvent extraction is leaching out of the insoluble solid structure of the oilseeds by using a volatile organic solvent such as acetone, butanol, n-hexane, isopropanol, etc. [4]. The use of these solvents for extraction is effective as it can extract most of the oil contained in the oilseed cells; however, the hazardous nature of the solvents, which often lead to fire explosion, relatively limits its uses [11]. The mechanical/hydraulic method or press method is the direct application of force on the seeds to press out the oil. This pressing method is relatively faster than others, but the expensive nature of the equipment used limits its uses. The rendering method is the slow heating of the seed to separate out the oil/fat from the seed.

Out of these three common extraction methods, solvent (n-hexane) extraction was the most commonly used and preferred method for extracting oil from seeds. Because of its extracting rate capacity, non-reactivity with oil, low cost, and high solvent power for fatty acids at relatively lower temperatures [11]. However, one way to adapt to the rules of green chemistry is to reduce the use of harsh organic solvents and adopt environmentally friendly, less hazardous, and nonflammable methods of extractions. [15] reported that the use of water as a solvent for the extraction of compounds that may be ingested into the human body is appropriate because an organic solvent-free extraction method could potentially eliminate the necessary solvent removal step and produce non-toxic products. Also, the qualities of any oil are indicated by some physicochemical properties, which provide an indication of both the nutritive and phytochemical qualities of the oil. These properties include peroxide, saponification, iodine, and acid values [16]. Phytochemical screening is also done to identify if the extracted oil has a new source of therapeutically and an industrially valuable compound which have medicinal significance.

Therefore, there is a need to exploit the potentiality and applicability of cold and hot water as solvents for the extraction of oils especially in plant materials like moringa seeds. The extracted oil will have an added advantage in that it can directly be used as food ingredients and in value addition in various food products with minimal health risk otherwise caused by organic solvent residues. Also, to retain all these oil qualities, care must be taken when storing them for a while. Because they readily undergo oxidative deterioration, which shortened their shelf-life. Hence, the present investigation was carried out to determine the possible effect of extraction methods and storage time on moringa seed oils' quality.

\section{MATERIALS AND METHODS}

\subsection{Materials}

Moringa oleifera seed was purchased at Girei's main market, Girei Local Government Area of Adamawa State, Nigeria. It was stored at ambient temperature till when needed. The reagents and chemicals used were sourced from the analytical laboratories of the departments of Food Science and Technology, Modibbo Adama University of Technology, Yola, and Biochemistry, Bayero University, Kano, Kano State. They were of analytical standard.

\subsection{Sample Preparation}

Moringa oleifera seeds were sorted to remove extraneous materials, after that dehulled and winnowed. The seeds collected were then grounded into a paste using an attrition mill. Three extractions, hot water, cold water, and solvent using $\mathrm{n}$-hexane, were used to extract oil from the paste. Completely Randomized Design (CRD) was adopted using 3 replications to determine each extraction method's effect on the yield and quality of oil extracted.

\subsection{Oil Extraction Processes}

The hot and cold water extraction methods described by Ilesanmi and Gungula [17] were adopted. The solvent extraction was carried out as described by Oladipo and Betiku [18] with modification. Specified quantity $(500 \mathrm{~g})$ of the moringa seed paste was wrapped with muslin fabric and placed in a conical flask (1000 ml). The flask was filled with $250 \mathrm{ml}$ of $\mathrm{n}$-hexane solvent and firmly secured at the end flask. The sample was allowed to stay overnight to extract the oil. The experimental setup was thereafter heated in a regulated water bath operated at $70^{\circ} \mathrm{C}$. The solvent and oil were decanted, and the solvent was recovered by a distillation process. Each experiment run was carried out in triplicate, and the mean with the standard deviation was calculated. The oil extracted was stored in well-labelled plastic bottles for analysis.

\subsection{Determination of the Percentage Oil Yield}

The parentage oil yield was calculated as described by Oladipo and Betiku [18]. 


$$
\begin{aligned}
& \text { Percentage oil yield (wt.\%) }= \\
& \frac{\text { weight of the oil extracted }(\mathrm{g})}{\text { weight of the paste }(\mathrm{g})} \times 100
\end{aligned}
$$

\subsection{Determination of the Chemical Proper- ties of the Extracted Oil}

The chemical properties of the extracted oil in terms of the peroxide, saponification, iodine, and acid values were determined according to American Oil Chemist's Society (AOCS) AOCS [19] standard method.

\subsection{Qualitative Screening of Phytochemical in the Extracted Oils}

Phytochemicals are chemical compounds produced by plants. They can also be regarded as compounds under research with unestablished effects on health and are not scientifically defined as essential nutrients. Their presence metabolites in plants produce some biological activity in man and animals, and it is responsible for their use as herbs. These compounds also serve to protect the plant against infection by microorganisms, predation by insects and herbivores, while some plants give their odours and or flavours, and some still are responsible for their pigments [20]. The extracted oils were screened for the following phytochemicals: alkaloids, saponins, flavonoids, tannins, coumarins, terpenoids, triterpenoids, steroids, anthocyanins, quinones, and emodins.

\subsubsection{Test for alkaloids}

Few drops (1 to 2) of Dragendorff's reagent (potassium bismuth iodide solution) were added to $1 \mathrm{ml}$ of the extracted oil sample inside a test tube. Reddish-brown precipitate indicates the presence of alkaloids [20]

\subsubsection{Test for saponins}

The ability of saponins to produce frothing in aqueous solutions was used as a screening test for saponins. About $1.5 \mathrm{~g}$ of extracted oil was shaken with water in a test tube. Persistent frothing was taken as preliminary evidence for the presence of saponins [20].

\subsubsection{Test for flavonoids}

The test for the flavonoid presence was carried out by adding a few drops (2 to 3 ) of concentrated sulphuric acid $\left(\mathrm{H}_{2} \mathrm{SO}_{4}\right)$ into $1 \mathrm{ml}$ of the extracted oil. Observation of orange to crimson red colouration indicates the presence of flavonoids.

\subsubsection{Test for tannins}

The test for tannin's presence was carried out adopting the method used by Fasola [21]. Five $(5 \mathrm{~g})$ of the extracted oil was introduced into an empty beaker $(50 \mathrm{ml})$ in which 3 drops of ferric chloride was added. A precipitate was taken as evidence for the presence of tannins.

\subsubsection{Test for coumarins}

Three $(3 \mathrm{ml})$ of $10 \% \mathrm{NaOH}$ was added to $2 \mathrm{ml}$ of aqueous extract formation of the extracted oil sample. The development of yellow colour in the solution indicates the presence of coumarins.

\subsubsection{Test for terpenoids}

The test for terpenoid's presence was carried out by adopting the method described by [22] About $5 \mathrm{ml}$ of the extracted oil sample was mixed with $2 \mathrm{ml}$ of chloroform, and $3 \mathrm{ml}$ of concentrated sulphuric acid $\left(\mathrm{H}_{2} \mathrm{SO}_{4}\right)$ was carefully added to form a layer. The reddish-brown colouration of the inner phase developed indicates the presence of terpenoids.

\subsubsection{Test for triterpenoids}

Ten (10 g) grams of the extracted oil were dissolved in $1 \mathrm{ml}$ of chloroform; $1 \mathrm{ml}$ of acetic anhydride was added after the addition of $2 \mathrm{ml}$ of Conc. $\mathrm{H}_{2} \mathrm{SO}_{4}$. The golden-yellow colour at the bottom of the solution shows the existence of triterpenoids [20].

\subsubsection{Test for steroids}

The extracted oil sample was treated with a few drops (1 to 2) of acetic anhydride and boiled. Few drops (1 to 2 ) of concentrated sulphuric acid $\left(\mathrm{H}_{2} \mathrm{SO}_{4}\right)$ from the sides of the test tube were added. The formation of a brown ring at the junction of the two layers and the turning of the upper layer to green shows the presence of steroids [20].

\subsubsection{Test for anthocyanins}

The test for anthocyanins' presence was carried out by adding a few drops (2 to 3 ) of concentrated sulphuric acid into $1 \mathrm{ml}$ of the extracted oil sample. The appearance of a yellowish-orange colour indicates the presence of anthocyanins.

\subsubsection{Test for quinones}

The test for quinones' presence was carried out by adding a few drops (2 to 3 ) of concentrated sulphuric acid into $1 \mathrm{ml}$ of the extracted oil samples. The formation of red colour indicates the presence of quinones.

\subsection{Quantitative Analyses of Phytochemical in the Extracted Oils}

After the qualitative screening of the phytochemical in the extracted oil samples, the quantitative analysis was conducted on these highly present phytochemicals.

\subsubsection{Determination of flavonoids}

Flavonoid was repeatedly extracted from $10 \mathrm{~g}$ of the extracted oil sample with the aid of $100 \mathrm{ml}$ of $80 \%$ aqueous methanol at room temperature. The mixture was filtered through a filter paper into a pre-weighed $250 \mathrm{ml}$ beaker. The filtrate was evaporated to dryness and weighed. The percentage of flavonoid was calculated by difference. 


\subsubsection{Determination of terpenoids}

The terpenoid content was determined as described by [23] with slight modifications. Ten $(10 \mathrm{~g})$ of the extracted oil sample was mixed with ethanol and allowed to stand for 24 hours. The extract was filtered, and the filtrate was extracted with petroleum ether using a separating funnel. The ether extract was treated as total terpenoids.

\subsection{Shelf-life Study of the Extracted Oil}

The oil extracted was kept inside plastic bottles and stored at room temperature for six months. Shelf-life stability of the extracted oil in terms of the peroxide, saponification, iodine, and acid values were determined according to AOCS [9] standard method at every two months interval for six months.

\subsection{Statistical Analysis}

The data obtained were analyzed statistically using two ways Analysis of Variance (ANOVA), and the Duncan New Multiple Range Test (DNMRT) was used to compare differences among means at a $5 \%(\mathrm{p}<0.05)$ level of significance.

\section{RESULTS AND DISCUSSION}

\subsection{The Percentage Yield of Moringa Seed Oil}

Figure 1 showed the percentage of oil yield of moringa seed using three different extraction methods. The percentage of moringa oil extracted was $30 \%$, 40\%, and $56 \%$ for cold water, hot water, and n-hexane extraction. It was observed that the cold water extraction method yielded the lowest extraction rate while the $n$-hexane extraction method yielded the highest extraction rate. A similar observation was reported by [24] for the extraction of oil from shea butter using traditional extraction methods (hot water) and solvent extraction using $\mathrm{n}$-hexane, whereby $\mathrm{n}$-hexane yielded more oil, $47.5 \%$, than the conventional method, which produced $34.1 \%$. The high polarity index of n-hexane, which aided its molecules to penetrate faster through the moringa seeds, was observed to cause the high yield obtained in the nhexane extraction method [25]. Also, the high yield obtained with n-hexane was possibly due to the absence of $\mathrm{OH}$ group, which has been reported to interfere with the extraction process of some oilseeds as reported by Oladipo and Betiku [18].

On the other hand, the solubility of cold and hot as polar solvents might have been negatively affected by the non-polar groups of the triglycerides of oilseeds (i.e. fatty acid chains), which, therefore, lead to reduce oil yield compared to $n$-hexane (a non-polar solvent). A similar observation was reported by [26] that the high polarity and dipole moment of the polar solvent such as water might have limited the lipids' solubility thus, leading to lower oil yield.

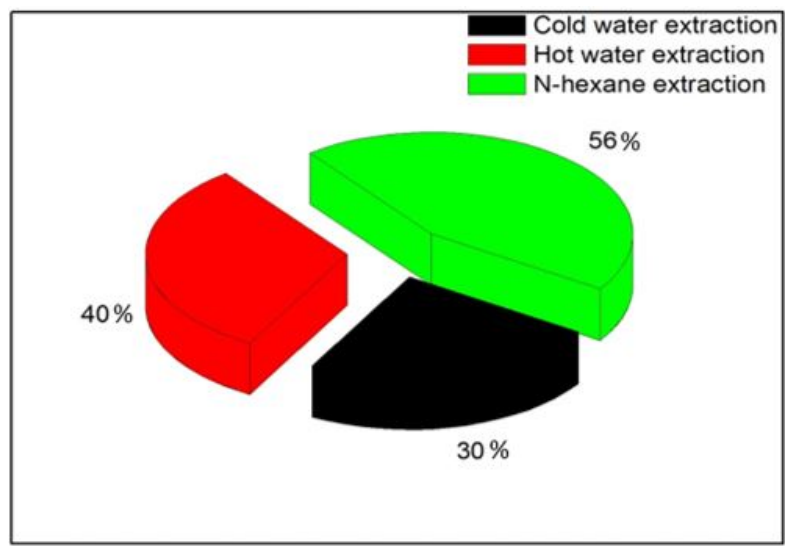

Figure 1: Percentage oil yield of moringa seed oil.

\subsection{Effect of Extraction Methods and Stor- age Time on the Chemical Properties of Moringa Seed Oil}

The chemical properties of the extracted moringa seed oil as affected by the extraction methods and storage time is presented in Table 1. The peroxide values of the fresh moringa seed oil ranged from 9.12 to $12.98 \mathrm{Meq} / \mathrm{kg}$. The values were significantly different $(\mathrm{p} \leq 0.05)$, with sample $\mathrm{C}$ having the highest value $(12.98$ $\mathrm{Meq} / \mathrm{kg})$, followed by sample B (10.36 Meq/kg), while sample A had the least value $(9.12 \mathrm{Meq} / \mathrm{kg})$. The values were significantly higher than $0.60-$ $2.10 \mathrm{Meq} / \mathrm{kg}$ [11] and $0.84-1.16 \mathrm{Meq} / \mathrm{kg}$ [13], but fell within $8.10-10.00 \mathrm{meq} / \mathrm{kg}$ reported by [8] and the standard specifications of peroxide value by $\mathrm{FAO} / \mathrm{WHO}$ [27]. The variations could be due to the varietal difference and method of extractions. There was a significant increase in the samples' peroxide values after 2,4 , and 6 months of storage compared to the fresh oil. The peroxide values increased from 18.75 to 21.02 to $22.50 \mathrm{Meq} / \mathrm{kg}$, 17.37 to 28.96 to $33.12 \mathrm{Meq} / \mathrm{kg}$, and 12.04 to 22.18 to $23.96 \mathrm{Meq} / \mathrm{kg}$ respectively for Samples A, B, and $\mathrm{C}$ after 2,4 , and 6 months storage time. The increase in the peroxide value with storage time could be due to peroxide oxidation over time. A similar increase in the peroxide value over time of storage was reported by [16] for palm oil.

The level of oil deterioration or the extent to which oxidative rancidity has taken place in the oil is usually accessed by the peroxide value [13]. A high peroxide value indicates lower stability to oxidative rancidity, while a low peroxide value indicates higher stability to oxidative rancidity. The increase in the peroxide values with storage time shows poor resistance of the oil to peroxidation during storage, thereby reducing the oils' qualities. Generally, the results showed that oil extracted with n-hexane was better than cold and hot water extracted oils. However, it was observed that the cold water and n-hexane extracted oils reserved their qualities better than hot water extracted oil after 6 months of storage.

The saponification values of the fresh moringa seed oil ranged from 184.17 to $222.17 \mathrm{mg} \mathrm{KOH} / \mathrm{g}$ oil. Sample B had the highest value $(222.17$ 
Table 1: Effect of extraction method and storage time on the chemical properties of moringa seed oil .

\begin{tabular}{|c|c|c|c|c|}
\hline Sample & Fresh & 2 months & 4 months & 6 months \\
\hline \multicolumn{5}{|c|}{ Peroxide value (Meq/kg) } \\
\hline A & $12.98 \pm 0.02^{a x}$ & $18.75 \pm 0.41^{a y}$ & $21.02 \pm 0.06^{b z}$ & $22.50 \pm 0.56^{b z}$ \\
\hline B & $10.36 \pm 0.07^{b x}$ & $17.37 \pm 0.81^{a y}$ & $28.96 \pm 0.66^{a y}$ & $33.12 \pm 0.12^{a z}$ \\
\hline $\mathrm{C}$ & $9.12 \pm 0.14^{c y}$ & $12.04 \pm 0.61^{b y}$ & $22.18 \pm 1.97^{b z}$ & $23.93 \pm 0.69^{b z}$ \\
\hline \multicolumn{5}{|c|}{ Saponification value (mg KOH/g oil) } \\
\hline A & $189.01 \pm 0.34^{b y}$ & $257.09 \pm 0.42^{b z}$ & $150.66 \pm 0.82^{a w}$ & $160.23 \pm 1.43^{a x}$ \\
\hline B & $222.17 \pm 1.97^{a y}$ & $258.86 \pm 0.40^{a z}$ & $110.43 \pm 1.04^{a z}$ & $122.72 \pm 0.36^{b x}$ \\
\hline $\mathrm{C}$ & $184.17 \pm 1.07^{b y}$ & $214.09 \pm 0.04^{c z}$ & $96.21 \pm 1.97^{c w}$ & $110.82 \pm 4.62^{b x}$ \\
\hline \multicolumn{5}{|c|}{ Iodine Value (mg/wij's) } \\
\hline A & $65.17 \pm 1.39^{a z}$ & $61.22 \pm 0.33^{a z}$ & $6.15 \pm 0.21^{b x}$ & $14.37 \pm 0.43^{a y}$ \\
\hline B & $60.49 \pm 0.76^{b z}$ & $50.59 \pm 0.17^{b y}$ & $6.93 \pm 0.06^{a w}$ & $16.25 \pm 0.94^{a x}$ \\
\hline $\mathrm{C}$ & $59.46 \pm 0.68^{b z}$ & $34.27 \pm 0.63^{c y}$ & $4.41 \pm 0.03^{c x}$ & $16.84 \pm 0.51^{b x}$ \\
\hline \multicolumn{5}{|c|}{ Acid Value (mg KOH/g oil) } \\
\hline A & $1.46 \pm 0.55^{b x}$ & $2.10 \pm 0.33^{b y}$ & $2.60 \pm 0.61^{c y}$ & $7.41 \pm 1.21^{b z}$ \\
\hline B & $1.30 \pm 0.65^{b x}$ & $3.88 \pm 0.51^{a y}$ & $4.09 \pm 0.39^{b y}$ & $7.81 \pm 0.43^{a z}$ \\
\hline $\mathrm{C}$ & $1.80 \pm 0.09^{a y}$ & $4.11 \pm 1.01^{a z}$ & $4.54 \pm 0.57^{c z}$ & $4.62 \pm 1.05^{a z}$ \\
\hline
\end{tabular}

$\mathrm{mg} \mathrm{KOH} / \mathrm{g}$ oil), followed by sample A (189.01 mg $\mathrm{KOH} / \mathrm{g}$ oil), while sample $\mathrm{C}$ had the least value (184.17 mg KOH/g oil). These values corroborated with the range of $181.10-252.34 \mathrm{mg} \mathrm{KOH} / \mathrm{g}$ oil [4, 27], $201.88-260.32 \mathrm{mg} \mathrm{KOH} / \mathrm{g}$ oil [11], and $200.67-253.32 \mathrm{mg} \mathrm{KOH} / \mathrm{g}$ oil [13] reported for different moringa seed oil. There was an increase in the samples' saponification value after 2 months of storage compared to that of the fresh oil. Sample A increased from 189.01 to $257.09 \mathrm{mg} \mathrm{KOH} / \mathrm{g}$ oil, sample B increased from 222.17 to $258.86 \mathrm{mg}$ $\mathrm{KOH} / \mathrm{g}$ oil, while sample C increased from 184.17 to $214.07 \mathrm{mg} \mathrm{KOH/g}$ oil. However, the oil samples' saponification values decreased after 4 months of storage compared to the result obtained after 2 months of storage time. The saponification values decreased from 257.09 to $150.66 \mathrm{mg} \mathrm{KOH} / \mathrm{g}$ oil, 258.86 to $110.07 \mathrm{mg} \mathrm{KOH} / \mathrm{g}$ oil and 214.07 to 96.21 $\mathrm{mg} \mathrm{KOH/g}$ oil, respectively for samples A, B, and $\mathrm{C}$ after 4 months of storage. Saponification values also indicate a significant increase $(p \leq 0.05)$ compared to that of 4 months of storage time. The values increased from 150.66 to $160.23 \mathrm{mg} \mathrm{KOH} / \mathrm{g}$ oil, 110.43 to $122.72 \mathrm{mg} \mathrm{KOH} / \mathrm{g}$ oil, and 96.21 to $110.82 \mathrm{mg} \mathrm{KOH} / \mathrm{g}$ oil, respectively, for samples A, $\mathrm{B}$, and $\mathrm{C}$ after 6 months of storage.

The fluctuation in the saponification values over storage time was observed due to changes in the weather conductions. High environmental temperature tends to increase the saponification values, while lower environmental temperature reduces the values. A similar observation was reported by [28] for Shea butter stored at different room temperatures. Generally, this decreasing trend with a storage time of this oil, showed that fatty acids have not been formed which can increase the saponification values, thus making the oil suitable for domestic use. [10] reported that a high saponification value implies the possible tendency to soap formations. Also, [16] said that the long-stored degraded oils are suitable for soaps and toiletry product productions. Base on the extraction methods used, the hot water had the highest saponification value, which means it will be more appropriate for the manufacture of soaps and cosmetics while cold water and n-hexane extracted oil will be adequate for domestic uses.

The iodine values of the fresh moringa seed oil ranged from 59.46 to $65.17 \mathrm{mg} /$ wij's. Sample A had the highest value $(65.17 \mathrm{mg} / \mathrm{wij}$ 's), followed by sample B $(60.49 \mathrm{mg} /$ wij's) while sample $\mathrm{C}$ had the least value $(59.46 \mathrm{mg} /$ wij's). These values corroborated with the range of $66.63-72.40$ $\mathrm{mg} / 100 \mathrm{~g}[3,4,10]$; however, the values were observed to be lower than the range of $78.68-91.37$ $\mathrm{g} / \mathrm{g}$ [11], $86.03-85.35 \mathrm{mg} / \mathrm{wij}$ 's [13], and the standard range of $80.00-106.00 \mathrm{mg} / \mathrm{wij}$ 's [27] reported for edible oil. It was observed that after 2 months of storage, the iodine values decreased from 65.17 to $61.22 \mathrm{mg} /$ wij's for sample A, 60.59 to 50.59 $\mathrm{mg} /$ wij's for sample B, and 59.46 to $34.27 \mathrm{mg} /$ wij's for sample $\mathrm{C}$ when compared with the fresh oil. Also, the iodine values decreased significantly ( $p$ $\leq 0.05$ ) at 4 months of storage compared to that obtained for 2 months of storage time. However, there was a slight increase in the iodine values obtained at 6 months of storage time compared to 4 months of storage time.

The fluctuation in the iodine values over storage time could be due to changes in weather conditions. [28] reported that higher storage temperature is favourable for lipase actions while lower storage temperature is unfavourable for lipase actions, increasing and decreasing the iodine values. These iodine values indicate a high level of unsaturation of fats and oils in the moringa seeds oil, while the oils are classified as a non-drying oil. Oils with 125 iodine value and above are classified as drying oils, $110-140$ are semi-drying oil, while less than 110 are non-drying oil [3]. Gen- 
erally, the decrease in the iodine values with storage time indicates that the oil has a low content of unsaturated fatty acids; thus, making it suitable for the production of soaps, lubricating oils, and lighting candles which traditionally requires fats or saturated oils. Also, because of the oil's nondrying nature, it will not attract the high interest of paints and coatings manufacturing industries unless it undergoes dehydration before use [2, 29].

The acid values of the fresh moringa seed oil ranged from 1.30 to $1.80 \mathrm{mg} \mathrm{KOH} / \mathrm{g}$ oil. Sample $\mathrm{C}$ had the highest value $(1.80 \mathrm{mg} \mathrm{KOH} / \mathrm{g}$ oil), followed by sample A (1.46 mg KOH/g oil), while sample B had the least value (1.30 mg KOH/g oil). These values are within the range of $1.35-2.76$ $\mathrm{mg} \mathrm{KOH} / \mathrm{g}$ oil [4] and $1.08-1.14 \mathrm{mg} \mathrm{KOH} / \mathrm{g}$ oil [13]. In contrast, it was significantly lower than $7.41-8.96 \mathrm{mg} \mathrm{KOH} / \mathrm{g}$ oil [14] and $2.88-8.25$ $\mathrm{mg} \mathrm{KOH} / \mathrm{g}$ oil [18] reported for other oil extracted from moringa seeds. These variations could be due to varietal differences, pre-processing conditions and extraction methods used. Atinafu and Bedemo [30] reported that the fatty acids that are majorly found in a triglyceride form might get hydrolyzed into free fatty acid, thereby increasing acid value during the extraction process. However, the high acid value implies decreased oil quality.

There was a significant increase in the samples' acid values after 2,4 , and 6 months of storage compared to the fresh oil. The acid values increased from 2.10 to 2.59 to $7.41 \mathrm{mg} \mathrm{KOH} / \mathrm{g}$ oil, 3.88 to 4.09 to $7.81 \mathrm{mg} \mathrm{KOH} / \mathrm{g}$ oil, and 4.11 to 4.54 to $4.62 \mathrm{mg} \mathrm{KOH} / \mathrm{g}$ oil, respectively for Samples A, B and C after 2, 4 and 6 months' storage time. The increase in the acid values with storage time could be due to the breakdown of the unsaturated fatty acids by hydrolysis or oxidation. A similar observation was reported by [14]. [14] also said that inadequate storage conditions or ageing of moringa seeds could cause an increase in acid values. This hydrolysis or oxidation that occurs over storage time is probably caused by a various agent such as, presence of moisture in the stored oil and lipase enzymes coming from the source or contaminating microorganisms. This observation supports the previous study that processing and storage conditions significantly affect the stored oils [16, 28].

\subsection{Phytochemical Screening of Moringa Seed Oils}

The results of the phytochemical screening of the extracted moringa seed oils were presented in Table 2. The result showed that alkaloids, saponins, tannins, triterpenoids, steroids, anthocyanins, quinines, and emodins were negative in the extracted oil samples in respective of the entreated methods. Coumarins were moderately present, while flavonoids and terpenoids were highly presented in all the extracted oil samples. Therefore, quantitative analysis was conducted on these highly present phytochemicals. Kadhim and AL-Shammaa [6] reported the presence of alkaloids, flavonoids, steroids, tannins, and terpenoids, with the absence of saponins and anthraquinone in the moringa seed extracts. While [22] reported the presence of alkaloids, terpenoids, flavonoids, tannins, saponins, and glycosides with the absence of phytosterols in the moringa oleifera leaves methanolic extract. The variations in these phytochemicals' occurrence could be due to the difference in the plant parts' difference even though they are all from moringa oleifera plant.

\subsection{Quantitative Analysis of the Phytochem- icals of Moringa Seed Oils}

Table 3 showed the results of the quantitative analysis of the extracted moringa seed oils. The flavonoids of the fresh moringa seed oils are $233.69 \mu \mathrm{g} / \mathrm{ml}, 249.97 \mu \mathrm{g} / \mathrm{ml}$, and $165.45 \mu \mathrm{g} / \mathrm{ml}$, respectively, for Sample A, B and C. These values were significantly higher than $20.73 \mathrm{mg} \mathrm{QE} / \mathrm{g}$ extract reported by [9]. In contrast, they are lower than the range of $402.64-519.95 \mathrm{mg} \mathrm{CE} / 100$ g [12] obtained elsewhere for moringa seed oil. These variations may be due to the varietal difference, pre-processing conditions, and extraction methods used. The result of the flavonoid after 2 months of storage showed that sample B increase slightly from 249.97 to $250.39 \mu \mathrm{g} / \mathrm{ml}$, likewise, sample C from 165.45 to $176.31 \mu \mathrm{g} / \mathrm{ml}$. However, sample A decrease from 233.69 to 230.06 $\mu \mathrm{g} / \mathrm{ml}$. At 4 months of storage time, the flavonoid contents decreased from $230.06-215.66 \mu \mathrm{g} / \mathrm{ml}$, $250.39-244.10 \mu \mathrm{g} / \mathrm{ml}$, and $176.31-172.88 \mu \mathrm{g} / \mathrm{ml}$, respectively for samples $\mathrm{A}, \mathrm{B}$ and $\mathrm{C}$ when compared with 2 months of storage time. However, at 6 months' storage time, the flavonoid contents increase from $215.66-220.23 \mu \mathrm{g} / \mathrm{ml}, 244.10-$ $249.36 \mu \mathrm{g} / \mathrm{ml}$, and $172.88-171.33 \mu \mathrm{g} / \mathrm{ml}$ respectively for samples A, B and C when compared with 4 months of storage time. The fluctuation in the flavonoid contents over storage time could be due to changes in the weather conditions.

Flavonoids, an antioxidant reported to have inhibited the initiation, promotion, and progression of tumours and reduce coronary heart disease [31] were appreciably present in moringa seed oils even after 6 months of storage time. Despite of this antioxidant property of flavonoid, it also protects the body against platelet aggregation, microorganisms, hepatotoxins, viruses, ulcers, free radicals, inflammation, and allergies [32]. This appreciable value obtained will increase the domestic uses of this oil. Based on the extraction methods, hot water extraction gave the maximum flavonoid contents while the n-hexane extraction method yielded the least amount of flavonoid contents; thus, the hot water extraction method is the adequate method among the methods employed in this study.

The terpenoids of the fresh moringa seed oils are $87.34 \mu \mathrm{g} / \mathrm{ml}, 150.17 \mu \mathrm{g} / \mathrm{ml}$, and $148.75 \mu \mathrm{g} / \mathrm{ml}$, respectively for Sample A, B and C. There was a significant $(p \leq 0.05)$ decrease in the terpenoid contents of the oil samples at 2 and 4 months of storage compared to the fresh oil. The terpenoid 
Table 2: Phytochemicals in extracted moringa seed oils.

\begin{tabular}{llll}
\hline Phytochemical & Hot Extraction & Cold Extraction & N-hexane Extraction \\
\hline Alkaloid & ND & ND & ND \\
Saponin & ND & ND & ND \\
Flavonoid & +++ & +++ & +++ \\
Tannins & ND & ND & ND \\
Coumarins & ++ & ++ & ++ \\
Terpenoid & +++ & +++ & +++ \\
Triterpenoid & ND & ND & ND \\
Streoid & ND & ND & ND \\
Anthocyanins & ND & ND & ND \\
Quinones & ND & ND & ND \\
Emodins & ND & & \\
\hline
\end{tabular}

Key: ND: Not Detected; +: Low Present; ++: Moderately Present; +++: Highly Present.

Table 3: Effect of extraction method and storage time on the level of phytochemical present in moringa seed oil.

\begin{tabular}{|c|c|c|c|c|}
\hline \multicolumn{5}{|c|}{$\begin{array}{l}\text { Samples } \\
\text { Total flavonoids }(\mu \mathrm{g} / \mathrm{ml})\end{array}$} \\
\hline A & $23369+0.66^{b z}$ & $23006+5.37^{b z}$ & $215.66+3.99^{b x}$ & $220.23+143^{b y}$ \\
\hline $\mathrm{B}$ & $249.97 \pm 0.16^{a z}$ & $250.39 \pm 0.26^{a z}$ & $244.10 \pm 0.27^{a y}$ & $249.36 \pm 0.98^{a z}$ \\
\hline \multirow{2}{*}{\multicolumn{5}{|c|}{$\begin{array}{l}\text { Total terpenoids }(\mu \mathrm{g} / \mathrm{ml}) \\
\text { 105.40 } \pm 1.10\end{array}$}} \\
\hline & & & & \\
\hline A & $87.34 \pm 0.42^{b z}$ & $86.05 \pm 1.60^{c z}$ & $79.30 \pm 0.94^{c y}$ & $80.78 \pm 0.48^{c y}$ \\
\hline B & $150.17 \pm 0.75^{a z}$ & $149.37 \pm 1.48^{a z}$ & $149.59 \pm 0.83^{a z}$ & $152.12 \pm 1.40^{a z}$ \\
\hline $\mathrm{C}$ & $148.75 \pm 0.67^{a z}$ & $138.88 \pm 1.48^{b y}$ & $126.65 \pm 0.56^{b x}$ & $127.73 \pm 0.58^{b x}$ \\
\hline
\end{tabular}

$a--c$ : Values bearing the same superscript in the same column are not significantly different $(\mathrm{p} \leq 0.05)$

$z--w$ : Values bearing the same superscript in the same row are not significantly different $(\mathrm{p} \leq 0.05)$

Key: $A=$ Cold water extraction; $B=$ Hot water extraction; $C=n$-hexane extraction.

contents decreased to $86.05 \mu \mathrm{g} / \mathrm{ml}$ and $79.03 \mu \mathrm{g} / \mathrm{ml}$ for sample A, $149.37 \mu \mathrm{g} / \mathrm{ml}$ and $149.59 \mu \mathrm{g} / \mathrm{ml}$ for sample B, and $138.88 \mu \mathrm{g} / \mathrm{ml}$ and $126.65 \mu \mathrm{g} / \mathrm{ml}$ for sample C. However, there was a slight increase at 6 months of storage compared to the values obtained at 4 months of storage time. The fluctuation in the flavonoid contents over storage time could be due to changes in the weather conditions. Based on the extraction methods, hot water extraction gave the maximum terpenoid contents while the cold water extraction method yielded the least amount of terpenoid contents; thus, the hot water extraction method is the adequate method among the methods employed in this study. Generally, the results obtained showed that storage time affected the oil sample's phytochemical content in different ways. The flavonoid contents increased, but the terpenoid contents decreased with storage time.

\section{CONCLUSIONS}

The study results showed that the extraction methods and storage time have a significant effect on the yield and qualities of the extracted oils. The percentage of oil yield was found to be dependent on the extraction method used; n-hexane gave the highest yield of $56 \%$, next was hot water with $40 \%$, while cold water gave $30 \%$. As the storage time increases, moringa seed oil from all the studied extraction methods would be highly competitive for industrial usage and less suitable for cooking due to its high peroxide values. The hot water extraction method will be more appropriate for the manufacture of soaps and cosmetics, while cold water and n-hexane extracted oil will be adequate for domestic uses. The oils may not be suitable for oil paint, varnishes, and surface coatings due to their nondrying attribute.

The study also reveals that the cold water and n-hexane extracted oils reserved their qualities better than hot water extracted oil after 6 months of storage. The cold water extracted oils are more stable and resistant to oxidative rancidity as the storage period progresses. Lastly, the study showed that storage time affected the oil samples' phytochemical content in different ways. The flavonoid contents increased while the terpenoid contents decreased with storage time. Among the extraction methods used, hot water had the highest level of phytochemicals throughout the storage period. The presence of these phytochemicals in the extracted oil showed their potentials as a good source of nutrients and medicines to improve the health status of humans consuming it. Further research needs to be carried out to investigate the effect of these analytical extraction methods on the micro and macro-nutrients of the extracted oil and the microbial load over the storage time.

\section{References}

[1] U. Biermann, W. Friedt, S. Lang, W. Luhs, G. Machmuller, J. Metzger, M. Rusch-Gen-Klass, H. Schafer, and M. Schneider, "New Syntheses with Oils and Fats as Renewable Raw Materials for the Chemical Industry," Angewandte Chemie International Edition, vol. 39, no. 13 , pp. 2206-2224, 2000. 
[2] S. Adebayo, B. Orhevba, P. Adeoye, J. Musa, and O. Fase, "Solvent Extraction and Characterization of Oil From African Star Apple (Chrysophyllum albidum) Seeds," Academic Research International, vol. 3, no. 2, pp. 178-183, 2012.

[3] M. Gore, "Extraction and Physicochemical Characterization of Oil from Maringa Stenopetala Seeds," IOSR Journal of Applied Chemistry, vol. 11, no. 1, pp. 1-7, 2018.

[4] B. Adejumo, A. Alakowe, and D. Obi, "Effect of Heat Treatment on the Characteristics and Oil Yield of Moringa oleifera Seeds," International Journal of Engineering Science, vol. 2, pp. 232-239, 2013.

[5] R. Saa, E. Fombang, E. Ndjantou, and N. Njintang, "Treatments and uses of Moringa oleifera Seeds in $\mathrm{Hu}$ man Nutrition: A Review," Food Science and Nutrition, vol. 7, pp. 1911-1919, 2019.

[6] E. Kadhim and D. AL-Shammaa, "Phytochemical Characterization using GC-MS Analysis of Methanolic Extract of Moringa oleifera (Family Moringaceae) Plant Cultivated in Iraq," Chemistry and Materials Research, vol. 6 , no. 5, pp. 9-26, 2014.

[7] S. Lalas and J. Tsaknis, "Characterization of Moringa oleifera Seed Oil Variety "Periyakulam 1.", Journal of Food Composition and Analysis, vol. 15, no. 1, pp. 6577, 2002.

[8] H. Ogbunugafor, F. Eneh, A. Ozumba, M. Igwo-Ezikpe, and J. Okpuzor, "Physico-chemical and Antioxidant Properties of Moringa oleifera Seed Oil," Pakistan Journal of Nutrition, vol. 10, pp. 409-414, 2011.

[9] C. Unuigbe, H. Okeri, O. Erharuyi, E. Oghenero, and D. Obamedo, "Phytochemical and Antioxidant Evaluation of Moringa oleifera (Moringaceae) Leaf and Seed," Journal of Pharmacy and Bioresources, vol. 11, no. 2, pp. 51-57, 2014.

[10] B. Ogunsina, T. Indira, A. Bhatnagar, C. Radha, S. Debnath, and A. Gopala-Krishna, "Quality Characteristics and Stability of Moringa oleifera Seed Oil of Indian Origin," Journal of Food Science and Technology, vol. 51, pp. 503-510, 2014.

[11] V. Efeovbokhan, F. Hymore, D. Raji, and S. Sanni, "Alternative Solvents for Moringa oleifera Seeds Extraction," Journal of Applied Sciences, vol. 15, no. 8, pp. 1073-1082, 2015

[12] M. Premi and H. Sharma, "Effect of Extraction Conditions on the Bioactive Compounds from Moringa oleifera (PKM 1) Seeds and their Identification using LC-MS," Journal of Food Measurement and Characterization, vol. 11, no. 1, pp. 213-225, 2016.

[13] B. Evbuomwan, D. Dick, and A. Chioma, "Comparative Analysis of Effect of Alternative Solvents on Extraction of Moringa oleifera Seed Oil," Chemistry Research Journal, vol. 2, no. 5, pp. 44-50, 2017.

[14] M. Ojewumi, M. Emetere, F. Olikeze, and D. Babatunde, "Alternative Solvent Combination Ratios for Moringa oleifera Seed Oil Extraction," International Journal of Mechanical Engineering Technology, vol. 9, no. 12 , pp. 295-307, 2018.

[15] P. Matshediso, E. Cukrowska, and L. Chimuka, "Development of Pressurised Hot Water Extraction (PHWE) for Essential Compounds from Moringa oleifera Leaf Extracts," Food Chemistry, vol. 172, pp. 423-427, 2015.

[16] C. Akin-Osanaiye, A. Gabriel, P. Alaje, and A. Omoniyi, "Effects of Different Storage Temperature on the Physicochemical Properties of Cooking Oils Available in Nigeria Markets," European Journal of Academic Essays, vol. 2 , no. 10 , pp. 7-14, 2015.

[17] J. Ilesanmi and D. Gungula, "Effects of Neem and Moringa seed Oil on Cookability and Palatability of Cowpea Grain Stored for Six Months," African Journal of Food Science, vol. 5, no. 9, pp. 522-528, 2011.

[18] B. Oladipo and E. Betiku, "Process Optimization of Solvent Extraction of Seed Oil From Moringa Oleifera: An Appraisal of Quantitative and Qualitative Process Variables on Oil Quality using D-Optimal Design," Biocatalysis and Agricultural Biotechnology, vol. 20,2019.

[19] AOCS, Official Methods and Recommended Practices of the American Oil Chemists Society, 6th ed. California: Champaign III, 2011, american Oil Chemists Society.

[20] N. Ramadass and N. Subramanian, "Study of Phyto- chemical Screening of Neem (Azadirachta indica), International Journal of Zoology Studies, vol. 3, no. 1, pp. $51-57,2018$.

[21] T. Fasola, "Screening Nigerian Plants for their Medicinal Importance," Journal of Science Research, vol. 6, no. 1 , pp. $51-57,2000$.

[22] G. Shanmugavel, K. Prabakaran, and B. George, "Evaluation of Phytochemical Constituents of Moringa oleifera (Lam.) Leaves Collected From Puducherry Region, South India," International Journal of Zoology and Applied Biosciences, vol. 3, no. 1, pp. 1-8, 2018.

[23] C. Indumathi, G. Durgadevi, S. Nithyavani, and P. Gayathri, "Estimation of Terpenoid Content and its Antimicrobial Property in Enicostemma litorrale," International Journal of ChemTech Research, vol. 6, no. 9, pp. 4264-4267, 2014.

[24] J. Ikya, L. Umenger, and A. Lorbee, "Effects of Extraction Methods on the Yield and Quality Characteristics of Oils from Shea Nut, Journal of Food Resource Science, vol. 2, no. 1, pp. 1-12, 2013.

[25] X. Yang, H. Lyu, K. Chen, X. Zhu, S. Zhang, and J. Chen, "Selective Extraction of Biooil from Hydrothermal Liquefaction of Salix psammophila by Organic Solvents with Different Polarities through Multistep Extraction Separation," BioResources, vol. 9, pp. 52195233,2014

[26] T. Russin, J. Boye, Y. Arcand, and S. Rajamohamed, "Alternative Techniques for Defatting Soy: A Practical Review," Food Bioprocess Technology, vol. 4, pp. 200-223, 2011.

[27] FAO/WHO, "Report of the 21st session of the codex alimentarius committee on fats and oils," February 2009.

[28] A. Saba, D. Tsado, and J. Okafor, "Determination of the Effect of Storage Time and Condition on the Properties of Shea Butter," Journal of Chemical Engineering \& Process Technology, vol. 9, no. 382, 2018.

[29] O. Abayeh, E. Aina, and C. Okounghae, "Oil Content and Oil Quality Characteristics of some Nigerian Oils Seeds," Science Forum: Journal of Pure and Applied Sciences, vol. 1, no. 1, pp. 17-23, 1998

[30] D. Atinafu and B. Bedemo, "Estimation of Total Free Fatty Acids and Cholesterol Content in some Commercial Edible Oils in Ethiopia Bahir DAR," Journal of Cereals and Oil seeds, vol. 2, no. 6, pp. 71-76, 2011.

[31] C. Ezeonu and C. Ejikeme, "Qualitative and Quantitative Determination of Phytochemical Contents of Indigenous Nigerian Softwoods," New Journal of Science, 2016.

[32] M. Barakat, S. Shahab, N. Darwin, and E. Zahemy, "Determination of Ascorbic Acid from Plants," Analytical Biochemistry, vol. 53, pp. 225-245, 1993. 